Research Article

\title{
Assessing commitment to principles of prescription writing for outpatients in teaching hospitals of Ahvaz: 2015
}

\author{
Mohammad Qolipour ${ }^{1}$, Farzad Faraji Khiavi $^{1}$, Ali Pourghayoumi ${ }^{2}$, Zahra Dashtinejad ${ }^{3}$, \\ Iman Mirr ${ }^{4}$
}

\begin{abstract}
${ }^{1}$ Department of Health Services Management, School of Health, Ahvaz Jundishapur University of Medical Sciences, Ahvaz, Iran, ${ }^{2}$ Department of Nutrition, School of Paramedical,

Ahvaz Jundishapur University of Medical Sciences, Ahvaz, Iran, ${ }^{3}$ Department of Anesthesiology, Shahid Beheshti Hospital,

Abadan, Iran,

${ }^{4}$ Department of Biostatistics and Epidemiology, School of Health, Ahvaz Jundishapur University of Medical Sciences, Ahvaz, Iran
\end{abstract}

Received: 8 December 2015

Revised: 9 December 2015

Accepted: 7 January 2016

\section{*Correspondence to:}

Dr. Mohammad Qolipour,

Email: Qolipour.m@ajums.ac.ir

Copyright: (C) the author(s), publisher and licensee Medip Academy. This is an open-access article distributed under the terms of the Creative Commons Attribution Non-Commercial License, which permits unrestricted non-commercial use, distribution, and reproduction in any medium, provided the original work is properly cited.

\begin{abstract}
Background: The observance of standard prescription principles by physicians increases the likelihood of proper treatment, its effectiveness and patients' recovery. The present study aims to explore the level of physicians' observance of prescription standards while visiting outpatients referring to teaching hospitals in Ahvaz.

Methods: This cross-sectional study was conducted on 550 prescriptions written for outpatients referring to (Ahvaz University of Medical Sciences) affiliated hospitals in 2015. In each prescription, issues related to legibility, medication form and order and identity information were extracted and recorded on a checklist prepared based on the World Health Organization guidelines. Each prescription was scored with a score range from 0 to 21 and then analyzed using descriptive statistics.

Results: The average number of items per prescription was 3.48; 1396 drugs $(72.78 \%)$ were written legibly; 1032 drugs $(58.81 \%)$ were prescribed incorrect forms; 1281 drugs $(66.07 \%)$ were prescribed in correct order; doctor's identity was written in $98.08 \%$ of the examined prescriptions; patient's identity was written in $80.36 \%$ of the prescriptions; and 1428 drugs were prescribed consistent with the standards of prescription.

Conclusions: Study results revealed that most of the examined doctors prescribed medications consistent with the standards of prescription; however, the two dimensions of medication form and order of use were not adequately noticed by doctors. Use of electronic prescriptions can improve the communication of prescriptions in teaching hospitals.
\end{abstract}

Keywords: Medications, Outpatients, Prescriptions

\section{INTRODUCTION}

Prescription is a written instruction by a medical practitioner intended for a specific treatment for a particular patient. ${ }^{1}$ Prescription is the last stage of a doctor - patient relationship and is considered as a medical deed. ${ }^{2}$ Writing prescriptions is one of the most common and powerful therapeutic tools for doctors. ${ }^{3}$ Prescriptions are written to improve life quality of patients. ${ }^{4}$ Therefore, the observance of prescription standards by doctors increases the likelihood of proper treatment, its effectiveness and patients' recovery. ${ }^{5,6} \mathrm{~A}$ good prescription is logical, evidence-based, clear, complete and able to improve treatment processes. ${ }^{7}$ The Medication process begins with doctors' medical orders. ${ }^{8}$ Medication errors are the most frequent medical errors and more than two-thirds of these errors are due to physicians' mistakes. Some of these medication errors 
include prescribing medications without paying attention to their complications and patients' medical histories or wrong medication, improper drug dosage, frequency or duration of use. ${ }^{9-11}$ Recent studies showed that medication error is the eighth leading cause of death worldwide and in the United States, $2-14 \%$ of patients are affected by it. Medication error is a preventive event that may cause inappropriate medication use or patients' harm. ${ }^{12}$ In Iran, 55 thousand medical errors are reported annually among which 10500 cases lead to death and 23000 to impairment. ${ }^{9}$ In a study conducted on dental prescriptions in Tabriz, $98.5 \%$ of the prescriptions was erroneous. The errors included medication name (94.9\%), route of administration (92.8\%), spacing doses $(72.4 \%)$ and the amount of medication use $(60.8 \%) .{ }^{13}$ Javadi et al (2008) study results indicated an average of 4 erroneous prescriptions out of every 1000 prescriptions. illegible handwriting on prescriptions was the most important and common causes of medication errors. ${ }^{2}$

Observance of prescription standards could avoid medication errors. A rational prescription is the one in which all mentioned standards are observed and clear information regarding the prescribed medications and the order of their use are provided. ${ }^{14}$ Prescribing high percentages of injecting drugs and antibiotics, ignoring drug interactions, not including drug use instruction in the prescriptions and illegibility of physicians handwriting were the most frequent prescription issues in Iran. $^{15}$ In a study in Hamadan, significant differences were observed in the average observance of prescription standards between post specialty physicians, physicians with specialty and interns who worked in teaching hospitals $(\mathrm{p}<0.05)$. However, no significant difference was reported between interns and specialized physicians and between residents and post specialty physicians $(p>0.05)$. Furthermore, no significant difference was observed in the level of prescription standards observance between general, specialized and post specialty physicians who worked in non-teaching hospitals.

In a study conducted in Isfahan, $84 \%$ of the examined prescriptions written by interns were illegible; in $82 \%$ of the prescription, generic names were used; in $6 \%$, drug form was not specified; in $4 \%$, dosage strength was not mentioned; in $63 \%$, drug use instruction was not specified; in $51 \%$, drug use spacing was not indicated; and only in $18.3 \%$, drug use instruction was specified adequately. ${ }^{16}$

Jeddi et al had reported that $88 \%$ of the received prescriptions by Medical Services Insurance Organization were legible; $72 \%$ contained drug form; $52 \%$ included drug use instruction; $80.12 \%$ contained patient's identity information; $93.96 \%$ contained physician's identity information and in average, on 3646 drugs, prescription principles were observed. ${ }^{1}$

A high quality prescription reflects a high quality treatment process in general. One of the best ways to review medication pattern in a society is to evaluate physicians' prescriptions. ${ }^{17}$ In Iran's health care reform program implemented since 2014, one of the important issues to improve the quality of outpatients services was an adequate observance of prescription standards by the doctors. $^{2}$ Thus, the present study aimed to analyse the level of physicians' observance of prescription standards while visiting outpatients referring to teaching hospitals in Ahvaz, Iran.

\section{METHODS}

This cross-sectional study was conducted on 550 prescriptions written for outpatients referring to affiliated hospitals of Ahvaz University of Medical Sciences in 2015. To determine the sample size, Cochran sampling formula was used $(\mathrm{p}=0.6 ; \mathrm{q}=0.4 ; \mathrm{z}=1.96 ; \mathrm{d}=0.2)$. After insertion into the formula, the sample size (n) was determined to be 23.05 for each specialty. However, in order to prevent loss of samples, the sample size was decided to be 25. Consecutive sampling was used. Prescriptions written by hospital-based physicians were analysed by a graduate student in the field of medicinal chemistry immediately after the meetings between patients and physicians. Therefore, 550 prescriptions were selected written by doctors in 22 different medical specialties (including endocrinology, ear, nose, and throat, cardiovascular, urology, digestion, lung, infant, internal, poisoning, skin, neurology, general physician, general surgery, infectious, genetics, orthopedics, hematology, ophthalmology, neurosurgery, psychology, obstetrician, and cardiovascular surgery). A data gathering form was developed based on WHO recommendations about commitment to principles of prescription writing ${ }^{1}$, in each prescription, related issues to drug form (1. Proper spelling; 2. Dosage form; 3. Proper spelling of dosage form), Medical order (4. The number of drugs; 5 . Drug dosage; 6. The order of drug use in Latin; 7. Medical recommendations; 8. Duration of drug use; 9. Instruction for drug use; 10. Drug use frequency), Physician's identity information (11. Name; 12. Family name; 13. Specialty; 14. Medical system code; 15. Signature), Patient's identity information (16. Name; 17. Family name; 18. Age; 19. Gender; 20.Weight) and eligibility (as the $21^{\text {st }}$ item) were analysed for each drug. If the handwriting was comprehensible without referring to any other person or the physician himself, it would be considered as eligible. Each of the mentioned 21 items had either 0 or 1 score and the total score for each prescription was in the range between 0 and 21 which was recorder on the prepared checklist. The scores were analysed using descriptive statistics (frequency and frequency percentage; SPSS16) and categorized in tables. For better analysis, the scores were divided into four equal score categories including weak (0-5.25), low intermediate (5.26-10.5), high intermediate (10.5-15.75) and good (15.76-21). 


\section{RESULTS}

The average number of items per prescription was 3.48 and totally 1918 items were prescribed in the 550 examined prescriptions. Among all 22 medical specialties, cardiologists and geneticists had prescribed the highest and the lowest number of drugs per prescription (5.2 and 2 items respectively). Moreover 685 $(35.71 \%)$ prescriptions were written for male patients and
$1233(64.29 \%)$ for female ones; $21.10 \%$ of the patients were below 20 years old, $32.20 \%$ between 20 and 40 years old and $46.70 \%$ above 40 years old.

Totally 1396 drugs name $(72.78 \%)$ were written legibly; $944(49.22 \%)$ drug names were written with correct spelling; $959(50 \%)$ drugs had correct form and 1243 $(64.81 \%)$ drug form were written with correct spelling.

Table 1: Frequency distribution of prescription standards observance (dimensions) in outpatients' prescriptions.

\begin{tabular}{|lllll|}
\hline Average of score & Maximum score & Written pharmaceutics & Percent & Variables \\
\cline { 2 - 5 } & & Number & 73.27 & legibility \\
\hline $0.73 \pm 0.44$ & 1 & 1396 & 53.81 & Pharmaceutical form \\
\hline $1.61 \pm 0.93$ & 3 & 1032 & 66.07 & Medical order \\
\hline $4.62 \pm 1.19$ & 7 & 1281 & 98.80 & Physician's identity information \\
\hline $4.94 \pm 0.23$ & 5 & 1895 & 80.36 & Patient's identity information \\
\hline $4.01 \pm 0.13$ & 5 & 1538 & - & Total \\
\hline $15.92 \pm 1.67$ & 21 & - & & \\
\hline
\end{tabular}

Table 2: Prescription standards observance based on specialty.

\begin{tabular}{|c|c|c|c|c|c|c|c|c|c|c|c|c|}
\hline \multicolumn{2}{|c|}{$\begin{array}{l}\text { Patient's } \\
\text { identity } \\
\text { information }\end{array}$} & \multicolumn{2}{|c|}{$\begin{array}{l}\text { Patient's } \\
\text { identity } \\
\text { information }\end{array}$} & \multicolumn{2}{|c|}{$\begin{array}{l}\text { Physician's } \\
\text { identity } \\
\text { information }\end{array}$} & \multicolumn{2}{|c|}{$\begin{array}{l}\text { Medical } \\
\text { order }\end{array}$} & \multicolumn{2}{|c|}{$\begin{array}{l}\text { Pharmaceutical } \\
\text { form }\end{array}$} & \multicolumn{2}{|c|}{ legibility } & \multirow[b]{2}{*}{ specialty } \\
\hline $\mathrm{p}$ & $\mathrm{n}$ & $\mathrm{p}$ & $\mathrm{n}$ & $\mathrm{p}$ & $\mathrm{n}$ & $\mathrm{p}$ & $\mathrm{n}$ & $\mathrm{p}$ & $\mathrm{n}$ & $\mathrm{p}^{* *}$ & $\mathrm{n}^{*}$ & \\
\hline 76.30 & 19 & 80 & 20 & 99.20 & 25 & 74.29 & 19 & 56.00 & 14 & 72 & 18 & Endocrinology \\
\hline 82.51 & 21 & 80 & 20 & 100.0 & 25 & 72.57 & 18 & 80.00 & 20 & 80 & 20 & Otorhinolaryngology \\
\hline 81.67 & 20 & 80 & 20 & 99.20 & 25 & 73.14 & 18 & 76.00 & 19 & 80 & 20 & Cardiology \\
\hline 77.56 & 19 & 80 & 20 & 100.0 & 25 & 73.14 & 18 & 70.67 & 18 & 64 & 16 & Urology \\
\hline 70.35 & 18 & 80 & 20 & 91.20 & 23 & 68.57 & 17 & 52.00 & 13 & 60 & 15 & Gastroenterology \\
\hline 79.19 & 20 & 80 & 20 & 95.20 & 24 & 75.43 & 19 & 77.33 & 19 & 68 & 17 & Pulmonology \\
\hline 73.66 & 18 & 80 & 20 & 98.40 & 25 & 64.57 & 16 & 53.33 & 13 & 72 & 18 & Pediatrics \\
\hline 71.38 & 18 & 80 & 20 & 99.20 & 25 & 57.71 & 14 & 40.00 & 10 & 80 & 20 & Internal \\
\hline 68.34 & 17 & 80 & 20 & 99.20 & 25 & 57.14 & 14 & 33.33 & 8 & 72 & 18 & Toxicology \\
\hline 70.51 & 18 & 84 & 21 & 99.20 & 25 & 60.00 & 15 & 41.33 & 10 & 68 & 17 & Dermatology \\
\hline 73.43 & 18 & 84 & 21 & 98.40 & 25 & 63.43 & 16 & 45.33 & 11 & 76 & 19 & Neurology \\
\hline 72.04 & 18 & 80 & 20 & 100.0 & 25 & 58.86 & 15 & 41.33 & 10 & 80 & 20 & General practitioner \\
\hline 73.84 & 18 & 80 & 20 & 96.80 & 24 & 61.71 & 15 & 50.67 & 13 & 80 & 20 & General surgery \\
\hline 69.45 & 17 & 80 & 20 & 100.0 & 25 & 60.57 & 15 & 46.67 & 12 & 60 & 15 & Infectious Disease \\
\hline 70.86 & 18 & 80 & 20 & 100.0 & 25 & 62.29 & 16 & 44.00 & 11 & 68 & 17 & Genetics \\
\hline 74.78 & 19 & 80 & 20 & 100.0 & 25 & 64.57 & 16 & 45.33 & 11 & 84 & 21 & Orthopedics \\
\hline 71.27 & 18 & 80 & 20 & 99.20 & 25 & 65.14 & 16 & 44.00 & 11 & 68 & 17 & Hematology \\
\hline 70.19 & 18 & 80 & 20 & 98.40 & 25 & 64.57 & 16 & 44.00 & 11 & 64 & 16 & Ophthalmology \\
\hline 74.13 & 19 & 80 & 20 & 100.0 & 25 & 64.00 & 16 & 42.67 & 11 & 84 & 21 & Neurosurgery \\
\hline 83.28 & 21 & 80 & 20 & 100.0 & 25 & 73.71 & 18 & 74.67 & 19 & 88 & 22 & Psychiatry \\
\hline 76.11 & 19 & 80 & 20 & 100.0 & 25 & 64.57 & 16 & 56.00 & 14 & 80 & 20 & $\begin{array}{l}\text { Obstetrics and } \\
\text { Gynecology }\end{array}$ \\
\hline 77.41 & 19 & 80 & 20 & 100.0 & 25 & 73.71 & 18 & 69.33 & 17 & 64 & 16 & $\begin{array}{l}\text { Cardiovascular } \\
\text { Surgery }\end{array}$ \\
\hline 74.47 & 1862 & 80.36 & 20.09 & 98.80 & 24.70 & 66.08 & 16.52 & 53.82 & 13.45 & 73.30 & 18.30 & Average \\
\hline
\end{tabular}


About the drugs prescribed by physicians, the number of $1220(58.39 \%)$ drugs, the dosage of $1276(66.53 \%)$, the order of drug use in Latin of 831 (43.33\%), Physician's recommendations 783 (540.82), the drug use duration of 1768 (92.18\%), the drug use instruction of 1603 $(83.58 \%)$ and the frequency of use of 1551 (580.87) drugs were mentioned. The physician's name, family name, specialty and medical system code was recorded in all of the examined prescriptions and the physician's signature was observed in 517 (94\%) of the prescriptions. Patient's identity (including name, family name, age and gender) were recorded in all of the examined prescriptions and his/her weight was observed in 10 $(1.8 \%)$ of the prescriptions (Table 1$)$.

On average, 1428 drugs were prescribed based on the prescription standards and the overall score of physicians' observance of prescription was 15.92 (or good).

The highest and the lowest level of prescription standards observance were in prescriptions written by psychologists $(\% 83.27)$ and dermatologists (\%68.33) respectively (Table 2).

\section{DISCUSSION}

The average score of observing prescription standards were 15.92 which was considered as good, which was consist with previous studies results. ${ }^{1-5,8}$ The average number of prescribed items per prescription was 3.48. The average numbers of items per prescription had been reported by the World Health Organization and in Iran 1.5 and 3.5 respectively. ${ }^{5-7,9}$ Moreover previous studies in Iran had reported the average number of items per prescription as 2.85 and $1.57 .^{18,19}$ Prescribing too many drugs may lead to increased incidence of medication complications, failure to follow medical orders, increased incidence or severity of interactions and ultimately discontinuation of treatment or prolonged medical treatment. ${ }^{20}$ Considering Iran as a developing country to which many pharmaceutical raw materials and a number of medications are imported, irrational prescription of medications makes great financial losses for the country in addition to its harmful effects on patients' health. ${ }^{21}$

Results showed that 1396 (72.78\%) drugs were written legibly in the examined prescriptions. In the analysis of prescription quality in medical records of hospitalized patients, in Rafsanjan hospitals, $70.7 \%$ of the prescriptions were written legibly. ${ }^{22}$ However, literature had reported different results about drugs legible writing in prescriptions ranging from $82.4 \%$ to $100 \% .^{23-25}$ Zeraati et al had reported a different results as $43.9 \%$ of the prescriptions written in Hamadan teaching hospitals and $54.5 \%$ in non-teaching hospitals were legible. ${ }^{5}$ To reduce medication errors initiated by illegible handwriting, electronic prescriptions are being used nowadays. 522000 medication errors in the United States have been prevented by the use of e- prescriptions. ${ }^{26,27}$
Correct forms of drugs were recorded in 1032 (53.81\%) prescribed items. Drug complete name and form was correctly recorded in $33.7 \%$ and $90.6 \%$ of prescriptions in Hamadan teaching hospitals and $49.2 \%$ and $90.6 \%$ in other hospitals of Hamadan, respectively. ${ }^{5}$ However, Heidari et al had reported that drug complete name and form was mentioned in $75 \%$ and $86.2 \%$ of the prescriptions, respectively ${ }^{22}$ which were not consistent with our results. Despite many problems in standard prescription writing in Iran, no specific course or educational program has been developed for medical students yet. Delfan and colleagues believed that the development of a specific course for prescription writing is a necessity which must be considered by the designers of medical curriculum. ${ }^{28}$

Results revealed that $1281 \quad(66.07 \%)$ drugs were prescribed with correct medical orders. In an Indian study, drug dosage was mentioned in $65 \%$ of the prescriptions. ${ }^{23}$ Al-Dhawailie et al reported that in the prescriptions written for hospitalized patients in a Saudi Arabia teaching hospital, correct frequency of drug use and correct drug dosage were written erroneously in $23 \%$ and $12 \%$ of the cases and $7 \%$ of the examined prescriptions were vague. $^{29}$ Moreover comparing teaching and nonteaching hospitals performance through prescription standards in Hamadan revealed that drug use instruction, dosage and duration of use were respectively mentioned in $25.1 \%, 68.5 \%$ and $60 \%$ of the prescriptions written in teaching hospitals and in $42.5 \%, 58.2 \%$ and $20 \%$ of the prescriptions written in non-teaching hospitals. ${ }^{5}$ Dental prescriptions assessment showed that drug dosage and drug use instruction were correspondingly mentioned in $100 \%$ and $94 \%$ of the examined prescriptions. ${ }^{25}$ In a study by Finji, drug dosage was not mentioned in $63 \%$ of the examined prescriptions. $^{30}$

In $98.08 \%$ of the examined prescriptions in the present study, the identity of the physician was mentioned. In a study on prescription writing skill among two groups of dentists, $98.1 \%$ of the prescriptions written by the first group and $22.8 \%$ of the prescriptions written by the second group had the dentist's signature; furthermore, $46.3 \%$ of the prescriptions written by the first group and $15.8 \%$ of the prescriptions written by the second group had medical system code as well. ${ }^{25}$ Also in prescriptions which were assessed by Zeraati et al (2014), all prescriptions had the doctor's signature. ${ }^{5}$ According to the existing insurance regulations in Iran, if the physician's name and signature are not mentioned in a prescription, the prescription is subject to medication deduction. Thus, physicians usually record their signatures in their prescriptions. The existence of this control system can explain the obtained high percentage of physicians' identity inclusion in this study.

Patient identity is important information that must be recorded in a prescription. Results revealed that in $80.36 \%$ of the examined prescriptions, the identity of the patient was mentioned. Studies which were done in Iran 
had reported a high rate of patients' identity recording in prescriptions ${ }^{5,25}$ compared with some other countries studies. ${ }^{6,23}$ This might be a result of the specific form of medical insurance booklets in which name, family name, age and gender of the patients are previously printed by the insurance companies.

\section{CONCLUSION}

Results indicated an adequate observance of prescription standards by Iranian physicians. However, the obtained high percentages of the items of physician's and patient's identity information were mostly due to the specific form of medical insurance booklets in which patient's identity information is previously printed by insurance companies and insurance companies' requirement for physician's signature. Moreover, the levels of physicians' observance of the most important items of drug form and drug use order were not satisfactorily. This study was solely conducted on the prescriptions written by physicians in teaching hospitals. Therefore, it is recommended to conduct future studies on prescriptions written in both teaching and non-teaching hospitals through designing a checklist based on medical insurance booklets' information without considering patients' and physicians' identity information. Moreover, in order to prevent medication errors related to illegibility of physicians' handwritings, it is recommended to apply prescription software or e-prescriptions.

\section{ACKNOWLEDGEMENTS}

It is a pleasure to thank all the patients participating in our study. This study was supported by Student Research Committee of Ahvaz Jundishapur University of Medical Sciences.

\section{LIMITATIONS}

Medication errors and drug interactions due to the prescription errors were not assessed in the study.

Funding: Student Research Committee of Ahvaz Jundishapur University of Medical Sciences Conflict of interest: None declared

Ethical approval: The study was approved by the Institutional Ethics Committee

\section{REFERENCES}

1. Jeddi MR, Jeddi FR, Mofrad MRR. Physicians' commitment to principles of prescription writing for outpatients insured by Medical Services Insurance Organization in Kashan. Director General. 2011;8(4):544.

2. Javadi M, Khui H, Solaimani F, Gholami K. Rational prescription of drug. Tehran: Andishe Mandegar. 2008:203-8.

3. Samadbeik M, Ahmadi M. Electronic prescription system: concepts and standards. Director General. 2013;10(2):312-24.
4. Classen DC, Metzger J. Improving medication safety: the measurement conundrum and where to start. Int J Qual Health Care. 2003;15(1):i41-7.

5. Zeraati F, Araghchian F, Esna'Ashari F, Saneii A, Torkashevand E. The comparison between observance of prescribing principles in Hamadan University of medical sciences teaching staff and non-teaching staff in 2012. Sci J Hamadan Uni Med Sci. 2014;21(1):66-71.

6. Alyamani NA, Hopf Y, Williams DJ. Prescription quality in an acute medical ward. Pharmacoepidemiol drug safety. 2009;18(12):115865.

7. Warren M, Gibb A, Walsh T. Antibiotic prescription practice in an intensive care unit using twice-weekly collection of screening specimens: a prospective audit in a large UK teaching hospital. J Hosp Infect. 2005;59(2):90-5.

8. Delfan B. Principals of logical prescription for medical groaps. Lorestan: Lorestan University of Medical Sciences Press. 2005:7-11.

9. Kazemzadeh GH, Hamedi A, Banejad Janatti F. Evaluating the impact of education via pamphlet on the medication errors of last year medical students. Med J Mashhad Uni Med Sci. 2013;56(4):204-10.

10. Dean B, Schachter M, Vincent C, Barber N. Causes of prescribing errors in hospital inpatients: a prospective study. The Lancet. 2002;359(9315):1373-8.

11. Dolatabadi M, Jalili RH. Patterns of physicians'drug preh1ion in Sabzevar Iran. Quarterly Journal of Sabzevar Uni Med Sci. 2009;16(3):161-6.

12. Force MV, Deering L, Hubbe J, et al. Effective strategies to increase reporting of medication errors in hospitals. J nurs admin. 2006;36(1):34-41.

13. Nezafati S, Maleki N, GholiKhani R. Copies of insurance quality dental care in Tabriz in the second half of 2005. Med J Tabriz Uni Med Sci. 2009;31(2):101-4.

14. Lofholm PW, Katzung BG. Rational prescribing and prescription writing. New York: McGraw Hill. 2001:1104-12.

15. Nabavizadeh $S$, Khoshnevisan F. Drug Interactions in prescriptions of general practitioners in Yasuj city. Present of Knowlegde. 2002;7(28):53-60.

16. Safaeian L, Kebriaeezadeh J, Hashemi-Fesharaki M, Salami S. Assessing the Prescription Writing principles in medical students' prescriptions during internship. J Isfahan Med School. 2014;32(277):28291.

17. Zare N. Effects of prescriber education in the public health insurer contracts with organizations in the city of Shiraz. J Mate Sci Eng. 2007;9(4):255-61.

18. Zareshahi R, Haghdoost A, Asadipour A, Sadeghirad B. Rational Usage of drug indices in the prescriptions of kerman medical practitioners in 2008. J Rafsanjan Univ Med Sci. 2012;11(6):52336.

19. Motamed N, Kashi A, SAFAAR M, Âlian S, Khademlou M, Eslamiyan R. Prescription writing 
ability of interns for common illnesses-Sari Medical School-summer 2004. Uni J Med Sci. 2006;16(51):101-11.

20. Bjerrum L, Søgaard J, Hallas J, Kragstrup J. Polypharmacy in general practice: differences between practitioners. British $\mathrm{J}$ Gen Pract. 1999;49(440):195-8.

21. Classen DC, Pestotnik SL, Evans RS, Lloyd JF, Burke JP. Adverse drug events in hospitalized patients: excess length of stay, extra costs, and attributable mortality. Surv Anesthesiol. 1998;42(3):130-1.

22. Heidari S, Khodadadi A, Ravari A, Asadi G, Fatehi Z. Prescription quality of medication chart of hospitalized patients in hospitals affiliated with Rafsanjan University of Medical Sciences, 2007. J Rafsanjan Uni Med Sci. 2012;11(5):437-48.

23. Phalke VD, Phalke DB, Syed MA, Mishra A, Sikchi S, Kalakoti P. Prescription writing practices in a rural tertiary care hospital in Western Maharashtra, India. The Aus Med J. 2011;4(1):4.

24. Ved P, Coupe T. Improving prescription quality in an in-patient mental health unit: three cycles of clinical audit. The Psychiatrist. 2007;31(8):293-4.

25. Akram A, ZamZam R, Mohamad NB, Abdullah D, Meerah SM. An assessment of the prescribing skills of undergraduate dental students in Malaysia. J Dent Edu. 2012;76(11):1527-31.

26. Hughes RG, Ortiz E. Medication errors: why they happen, and how they can be prevented. J Infus Nurs. 2005;28:14-24.

27. Jones S, Moss J. Computerized provider order entry: strategies for successful implementation. J Nurs Admin. 2006;36(3):136-9.

28. Delfan B, Mosaddegh E. Evaluation of essentiality of prescription education from viewpoint of general practitioners and chief managers of medical colleges. Iran J Med Edu. 2007;7(2):76-81.

29. Al-Dhawailie A. Inpatient prescribing errors and pharmacist intervention at a teaching hospital in Saudi Arabia. Saudi Pharm J. 2011;19(3):193-6.

30. Fijn R, Van den Bemt P, Chow M, De Blaey C, Jong-Van den Berg D, Brouwers J. Hospital prescribing errors: epidemiological assessment of predictors. British J Clin Pharmacol. 2002;53(3):326-31.

Cite this article as: Qolipour M, Khiavi FF, Pourghayoumi A, Dashtinejad Z, Mirr I. Assessing commitment to principles of prescription writing for outpatients in teaching hospitals of Ahvaz: 2015. Int J Basic Clin Pharmacol 2016;5:79-84. 